\title{
Research and Practice of rail traffic signal and control major construction
}

\author{
Hu Xiaojuan, Hu Liqiang, Zhao Nan \\ Electrical and Electronic Engineering of Shijiazhuang Railway Institute, Shijiazhuang, China, \\ 050000
}

Keywords: Rail traffic signal and control; building objectives; overall planning; embodiments

\begin{abstract}
The technology content railway companies increasingly urgent need for a large number of highly educated, professional and technical personnel to master modern technology. In this paper, the social background of China Railway Development to explore on rail traffic signal and control professional goal of building the overall planning and implementation of programs proposed rail signaling and control professional a reasonable position, and its construction curriculum system, teachers team construction, construction of schools and enterprises to build and implement the reform of the teaching mode of the base were discussed for rail signaling and control professional development to contribute.
\end{abstract}

\section{Introduction}

According to the national long-term railway network plan, boosting economic development as the basic industry, in 2020 the high-speed railway network will reach more than 16,000 kilometers. Urban rail transport, according to statistics from the Ministry of Construction and Urban Rail Transit Association published, 2015, the total mileage of urban rail transit operators over $2500 \mathrm{~km}$. Average per km of railways 20 railway operation and maintenance staff calculate that "five" period demand for railway signal professional shortfall of more than 20,000 workers. Especially the "7.23" Wenzhou motor car rear-end accidents, the demand for high-skilled talents signal is imminent. Urban rail, according to the study of subway employees demand data statistics, per kilometer on average five signal lines calculated that demand during the second five of the professionals will reach 12,500 . Talents scale on existing relevant professional colleges and universities can not meet the needs of the employer.

Through visits to research employers and the graduates back its order, we understand that the national high-speed rail into the next era background, national, corporate demand for railway construction and management personnel with new features. Railway signal professional must evolve along with railways and local urban rail transit, targeted personnel training, training students should be able to adapt to the future employment needs. This paper will present a training program complete professional teachers, teaching reform and the establishment of school and enterprise training base of railway signal program, provide a reference for the control signal and the major construction of rail transit.

\section{Target rail traffic signal and control major construction}

Rail traffic signal explore professional "training for the industry, employment-oriented curriculum and teaching, teaching theory and application practice of combining" the new talent training mode. Including the establishment of professional development strategies and objectives, training plan, recognizing the practice, the preparation of production practice, course syllabus and other teaching documents, classroom teaching practice and reform measures, with a view to institutions of higher learning and other related specialty Engineering professional training model reform as a reference to improve the overall level of higher education.

Orbital traffic signal control professional and teaching reform, solve the disconnect between theory and application of teaching, and industry professionals to achieve seamless education needs to adapt to the current period of great development of rail transit, high-speed rail, urban rail and the 
use and maintenance of existing railway rail transportation signaling and control professionals urgent needs, improve the quality of employment of graduates.

Correctly guide the graduates from their own actual situation, the reasonable expectation of employment adjustment to maximize the overall quality of their individual strengths, rational understanding the employment situation, identify their own position, to successfully enter the workplace. Opened to rail traffic signal class graduates career planning education, so that graduating students to recognize professional railway signal and other universities of similar professional distinction, relying unprecedented employment opportunities for large-scale development of the railway brought, to study railway The high precision and advanced technology, the railway as the primary target individual career orientation.

\section{The overall planning and control rail traffic signal major construction and embodiments}

Professional construction of rail traffic signal classes should follow task-driven, market-oriented principles, combined with the actual adjustment professional curriculum; strengthening colleges, enterprises and schools, and to improve rail traffic signaling and control teaching system; strengthen the teaching staff, the formation of professional academic echelon; demodulation theory and Application of Teaching disjointed contradictory, variable proven to inspire interactive.

\section{Rail traffic signal and control professional a reasonable position}

Mining and development of the existing academic strengths of urban rail transit industry background as well as transportation, electrical, civil, etc. and advantages Railway Bureau, the engineering bureau scientific and technological cooperation with the surrounding rail transportation industries and disciplines will dispatch services, electrical services, maintenance talents knowledge jobs, capacity and quality demands, create trade and effective link mechanism schools, industry needs to reverse the contradiction between the university personnel training by schools and enterprises to build other models.

Construction of curriculum, to develop training programs to prepare cognition practice, production practice, graduation practice teaching and course syllabus and other documents to establish rail signaling and control professional indications in Universities (cutting-edge, heterogeneity, applicability, etc.) building strategies and objectives.

\section{Construction of Curriculum System}

We need three to four times a wide range of market and business research, writing research reports provide the basis for the revision of the new professional training programs; invite industry experts to the school to track traffic signal and control construction professional guidance, and cooperation between enterprises to determine the professional talent professional positions and professional training objectives. By professional leaders, business professionals, teachers consisting course construction team, according to "OK job or job group - Analysis of typical job tasks induction fields of action - the development of fields of study," the process, improve the curriculum system (such as shown in FIG. 1). 


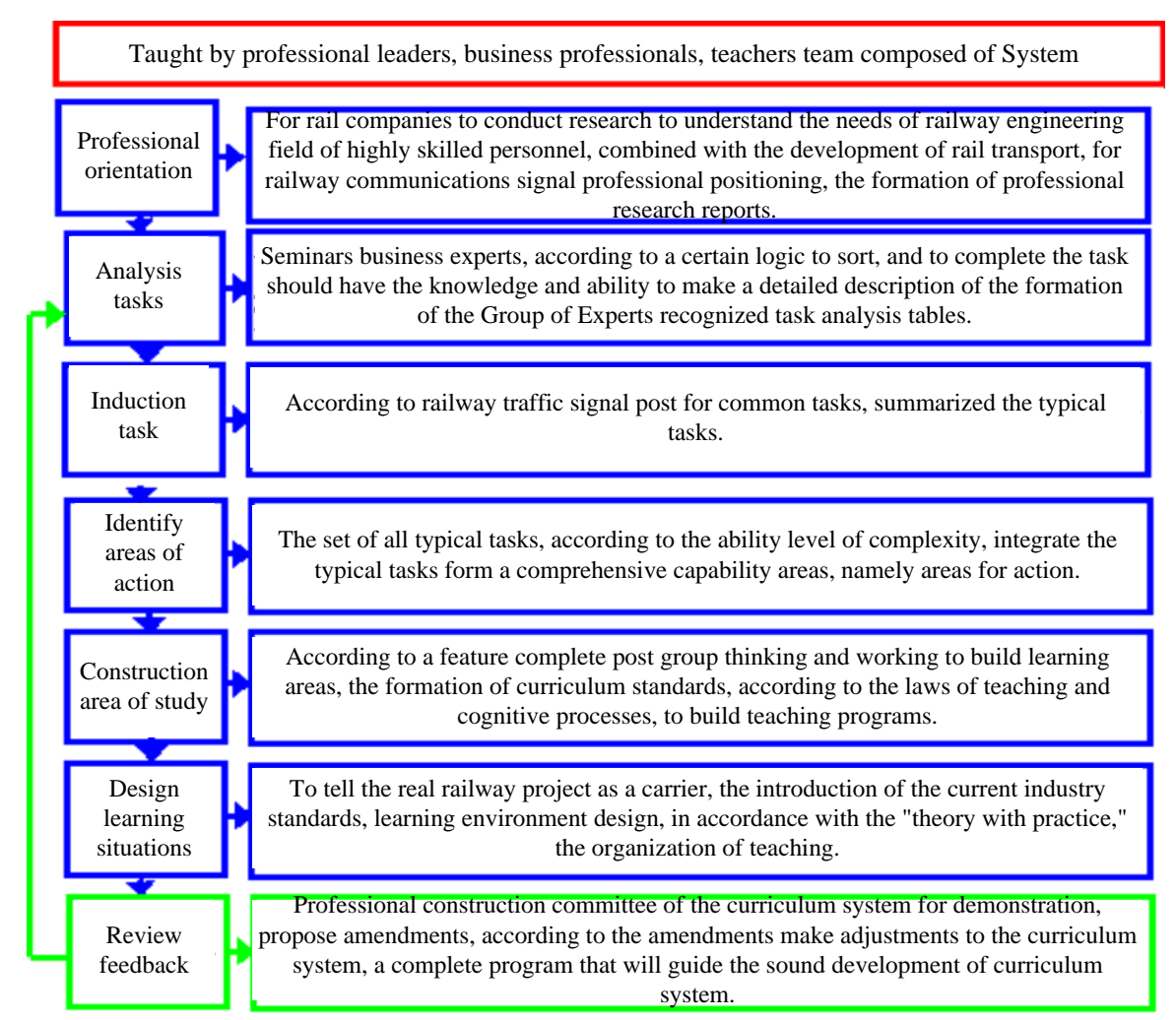

\section{Professional teacher team building}

Program 1 to send out two professional teachers to learn, arrange 1 to 2 professional teachers to business post teaching practice; establish mentoring mechanism, cultivate a group of scientific backbone, form of teaching and research backbone of the team and team structure. Send two or more teachers to participate in various conferences or go out training, learning and training through out, broaden the horizons of teachers, improve the professional level of teachers, train outstanding academic leaders, constantly optimize the teaching staff, explore the characteristics of professional "professional teachers "Teachers Construction mode. In Shijiazhuang Railway Institute, for example, since 2004, specializing in rail signaling and control planned send seven teachers have to Lanzhou Jiaotong University, Beijing Jiaotong University for further study. 2013 should be invited to Huang Shuo railway Suning branch, rail signaling and control professional teachers for teaching and research branch nearly 150 employees were trained in a month-long railway-related knowledge. During the training, the railway line has been to conduct research to observe and help companies solve some technical problems in the field. In order to further strengthen academic exchanges, invite experts railway signal DONG Yu Xi Engineering, rail experts Rong Jianguo come to the school to do an academic report, the organization "electrical tutor forum" academic report five games. In this process, the teachers' enthusiasm and ability to research is also improved in 2014, presided over the provincial natural science fund projects eligible for two (General Program, Young Scientists Fund and each one), bureau-level project two horizontal issues 4 . EI journal papers retrieved three core journals 3; an invention patents, apply one.

\section{Construction of school and enterprise of training base}

Exploration and rail traffic signal control and railway administrations to build professional curriculum, gauge theory and practical teaching, joint implementation of the training process running mode, truly "training for the industry"; relying on high-speed rail base, strengthen school-enterprise cooperation, the establishment of industry information package, professional docking industry demand for qualified personnel packets and packets carry out professional dynamic adjustment, and actively adapt to high-speed rail industry to bring development opportunities and personnel needs; adhere to the complementary advantages, resource sharing, mutual benefit and win-win, with production line project cooperation ties to improve the quality of personnel training, strengthen basic focus on capacity building, promoting the Board management 
system, electrical works Institute of cooperation to build, strengthen order training, establish school-enterprise sharing talents, equipment sharing, technology sharing, complementary school-enterprise culture, school depth cooperation between enterprises management interoperability, enhance professional competence and influence in the industry.

Based on the high-speed rail development trends, talent demand and Graduates flow direction for system analysis, the establishment of "industry", "professional docking industry", "talent needs" three packs form a "initiative to adapt, moderate advance, specialty construction Interaction and industrial development, "the professional building mechanisms.

Annual organization of professional teachers to high-speed rail transportation worksites to conduct research, according to railroad job development requirements and rail new technology, new equipment, new regulations apply, to update course content; binding change high-speed rail business production organization, continue to optimize course system and the form of teaching organization, dynamic management, timely adjustment, a "business technology upgrades - Teaching adjustment" mechanism (see Figure 2).

Currently, in the professional construction, Shijiazhuang Railway Institute have identified a training agreement with Suning Branch Huang Railway; working with Shijiazhuang Marshalling south, east yard practice base agreement signed; and CLP Branch Group 54 to build the "city Rail traffic control communication with the Laboratory "is progressing well, has purchased 200 million urban rail transportation equipment, installation and commissioning now; and Shijiazhuang Railway Co has made contact, the proposed means of Shijiazhuang City, the subway station of opportunity, and relevant industry enterprises and departments to establish friendly and cooperative relations, to the railway signaling and control students completed the integration of school and enterprise training base.

\section{Reform teaching mode}

Teaching methods directly affect the quality of teaching, teachers should not only teach theory books, but also the railway signaling industry new technology into their teaching, combined with on-site practical issues, narrowing the field of theoretical teaching and implement gap, in particular to strengthen the design process chain of custody to ensure the quality of teaching, students of professionalism; at the same time, to change the traditional "one textbook, a piece of chalk, a blackboard" teaching methods, the use of some advanced e-learning methods, enable students to multiple perspectives, diversity to master the professional knowledge, becomes cramming heuristic-based research, case type, such as teaching models, strengthen student-centered teaching philosophy, the training and knowledge transfer methods and research capabilities combine to gradually form students active learning and study habits and ability, so that teachers complete from the "teach you" to "help you learn" role change.

Secondly, the reform of assessment methods, the implementation of development evaluation. Not only concerned about student academic performance, but also focus on the discovery and development of students' potential, so that their overall quality can be improved. Relying on "innovation and entrepreneurship students Training Program" and "Electronic Circuit Design Competition" scientific training programs, professional-class teaching reform to train students' ability as a starting point, adjust teaching content, using the existing test methods reform, exploration A more scientific, more rational comprehensive examination methods, to provide students with scientific research, innovation, experiment and practice platform, a comprehensive educational environment; and finally, through the introduction of professional, scientific literature search and the frontier and research methods and a series of programs to help students build professional knowledge system and the overall concept. 


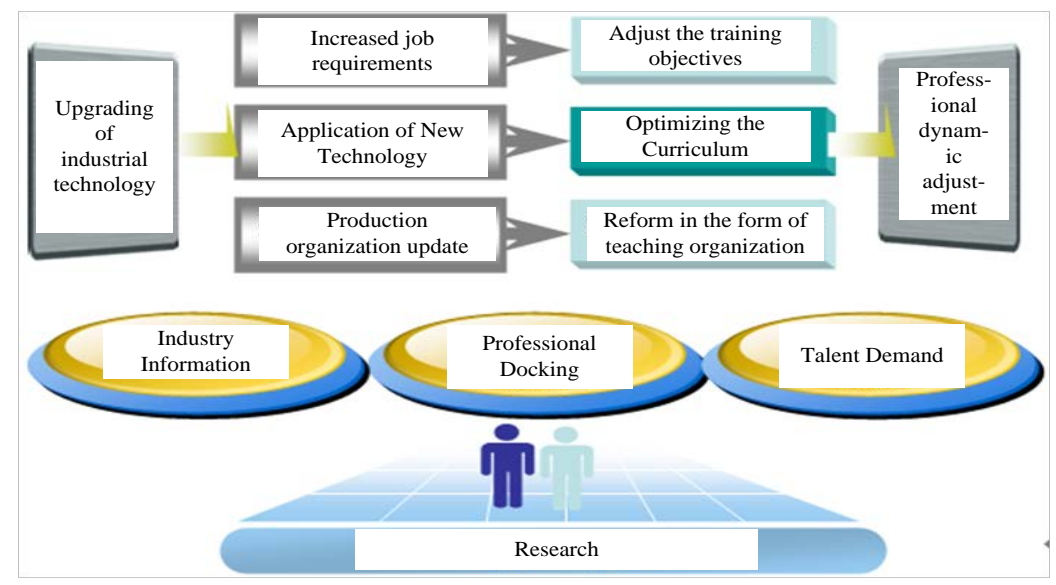

Figure 2. Rail traffic signal and control of a professional dynamic adjustment process diagram

\section{Conclusion}

Signal technology is one of the core technology to support railway and urban rail transport modernization, track signaling and control professional characteristics, determine the professional training specifications must have a strong operational skills, analytical skills, adaptability. With the development of railway and urban rail transit, companies continue to reform not only the equipment, personnel management, and other aspects of the constantly undergoing change, especially in recent years of a larger reform of the railway, resulting Railway talent demand has changed, therefore, railway signal professional development to meet the needs of the field, to the growing strength of growth, professional development and reform is its only way.

By rail signaling and control professional to raise the overall railway communications professional services railway electrical technology development capability of the signal, the formation of specialized flexible dynamic adjustment, professional building mechanisms to achieve professional and industrial connection; professional training programs and curriculum system a more rational design; closely follow the development of high-tech railway signaling, constantly updated course content, so that course content and professional standards and docking; and electric service enterprises jointly build "advanced equipment and facilities" production practice base, to practice teaching Process and electric service production process docking practice base number, function meet practice teaching, research and railway electricity enterprise staff training, technical competition, vocational skills certification requirements; faculty title, education, type, age, academic structure more reasonable, the quantity and quality of teachers meet the requirements of the railway signal high skilled talents; make rail signaling and control professional to become the professional practice of educational reform university leader.

\section{Reference}

[1] Gershon RRM. Public transportation: advantages and challenges [J]. Journal of Urban Health, 2012,82(1): 7-9.

[2] Hickman MD, Wilson NHM. Passenger travel time and path choice implications of real-time transit information [J]. Transportation Research Part C: Emerging Technologies, 2011,3(4):211-226.

[3] Verma A, Dhingra SL. Feeder Bus Routes Generation within Integrated Mass Transit Planning Framework [J]. Journal of Transportation Engineering, 2012,131(11): 822-834.

[4] Shrivastav P, Dhingra SL. Development of Feeder Routes for Suburban Railway Stations Using Heuristic Approach [J]. Journal of Transportation Engineering, 2011: 334-341.

[5] Daganzo CF, Pilachowski J. Reducing bunching with bus-to-bus cooperation [J]. Transportation Research Part B: Methodological, 2011,45(1): 267-277. 
[6] Wendler E. The scheduled waiting time on railway lines [J]. Transportation Research Part B: Methodological, 2007,41(2): 148-158.

Acknowledgements: This article is "Shijiazhuang Railway Institute Twelve Five Plan of Education Subject (Y201403)" research 